\title{
Fifteen-year follow-up of Italian families affected by arginine glycine amidinotransferase deficiency
}

\author{
Roberta Battini ${ }^{1 *}$, M. Grazia Alessandri ${ }^{1}$, Claudia Casalini ${ }^{1}$, Manuela Casarano $^{1}$, Michela Tosetti ${ }^{2}$ \\ and Giovanni Cioni ${ }^{1,3}$
}

\begin{abstract}
Background: Arginine:glycine amidinotransferase deficiency (AGAT-d) is a very rare inborn error of creatine synthesis mainly characterized by absence of brain Creatine (Cr) peak, intellectual disability, severe language impairment and behavioural disorder and susceptible to supplementary $\mathrm{Cr}$ treatment per os. Serial examinations by magnetic resonance spectroscopy are required to evaluate $\mathrm{Cr}$ recovery in brain during treatment of high doses of $\mathrm{Cr}$ per os, which have been proved beneficial and effective in treating main clinical symptoms.

A long term study with detailed reports on clinical, neurochemical and neuropsychological outcomes of the first Italian patients affected by AGAT-d here reported can represent a landmark in management of this disorder thus enhancing medical knowledge and clinical practice.
\end{abstract}

Results: We have evaluated the long term effects of $\mathrm{Cr}$ supplementation management in four Italian patients affected by AGAT-d, correlating specific treatments with serial clinical, biochemical and magnetic resonance spectroscopy examinations as well as the neuropsychological outcome by standardized developmental scales. Consecutive MRS examinations have confirmed that $\mathrm{Cr}$ depletion in AGAT-d patients is reversible under $\mathrm{Cr}$ supplementation. $\mathrm{Cr}$ treatment is considered safe and well tolerated but side effects, including weight gain and kidney stones, have been reported.

Conclusions: Early treatment prevents adverse developmental outcome, while patients diagnosed and treated at an older age showed partial but significant cognitive recovery with clear improvements in adaptive functioning.

Keywords: Creatine synthesis defect, Magnetic resonance spectroscopy, Creatine supplementation, Longterm outcome, AGAT deficiency

\section{Background}

Arginine:glycine amidinotransferase (AGAT, OMIM 602360) deficiency (AGAT-d) is a very rare inborn error of creatine $(\mathrm{Cr})$ synthesis described in 2000 in an Italian family and successively confirmed by molecular and enzymatic analysis $[1,2]$. This disorder is caused by a deficiency of the first enzyme involved in $\mathrm{Cr}$ synthesis (Fig. 1), resulting in a commonly recognized biochemical pattern represented by low Guanidinoacetic acid (GAA) concentrations in plasma and urine and low/undetectable

\footnotetext{
* Correspondence: rbattini@fsm.unipi.it

'Department of Developmental Neuroscience, IRCCS Fondazione Stella Maris, Viale del Tirreno 331, Calambrone, 56128 Pisa, Italy

Full list of author information is available at the end of the article
}

brain $\mathrm{Cr}$ detectable by magnetic resonance spectroscopy (MRS). Main clinical symptoms of this disorder are intellectual disability, severe language impairment and behavioural problems. Similar to guanidinoacetate-methyltransferase deficiency (GAMT-d), another $\mathrm{Cr}$ synthesis defect, it is susceptible of supplementation therapy with high doses of Cr monohydrate per os [3-6].

Since the first reports on two Italian families $[1,2,6]$ 15 years ago, only 16 patients from eight families of different ethnic origins have been diagnosed [7].

There is a substantial lack of information on the outcome of these patients, due to recent detection of disease, limited number of years of substitutive treatment and paucity of identified patients. So far, a longitudinal 9-year study on a 


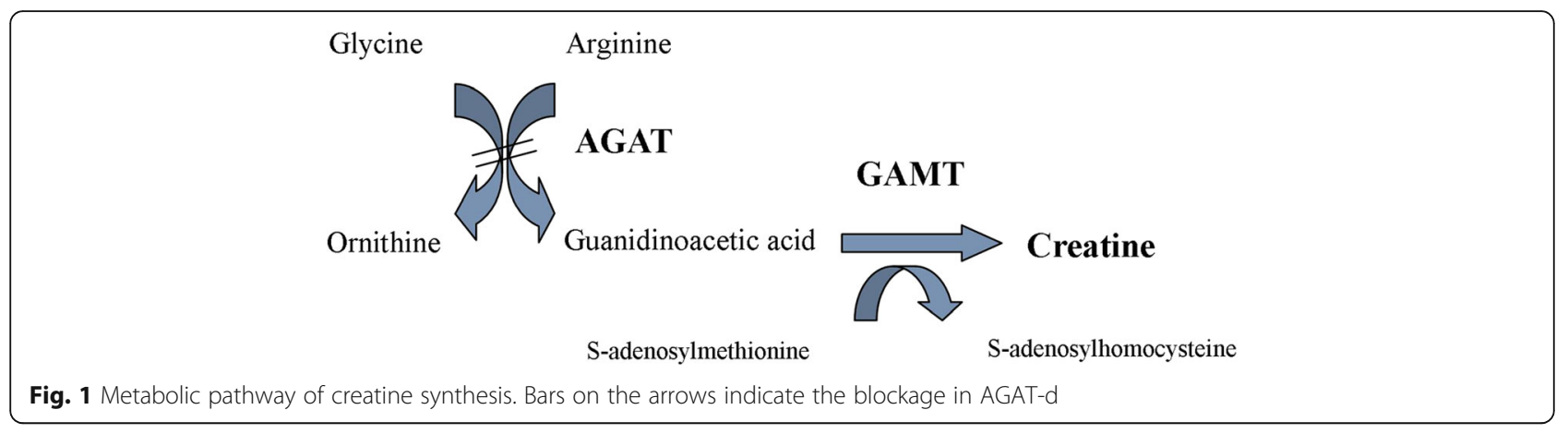

AGAT patient [8] and a recent review with some data on all AGAT-d patients identified worldwide [7] have been reported. In particular, this review confirms that the main clinical symptoms of the disease are present in all patients and reveals that myopathic symptoms are also present in about half of them, particularly in patients with a late diagnosis (from 6 to 23 years). Seizures and behavioural problems have also been reported in a few cases [7]. Chronic $\mathrm{Cr}$ supplementation of varying dosages, ranging from 100 to $800 \mathrm{mg} / \mathrm{Kg} /$ day, restores brain $\mathrm{Cr}$ to $60-95 \%$ of normal in all patients monitored by MRS, improving cognitive and motor symptoms [7], with the exception of one patient in which it increased only to $18 \%$ of normal even after 7 years of supplementation [7, 9]. Since blood and cerebral Cr concentrations during treatment have not been reported in all patients, it is not possible to establish a correlation, if any, between brain and blood levels. This information would be interesting in order to tailor treatments for each patient, thus avoiding high dosages and potential metabolic dysregulation. Therefore in this paper, we report the clinical data observed in our AGAT-d patients over a long period.

In fact, $\mathrm{Cr}$ treatment in these patients was pioneering and required constant adjustments according to clinical and biochemical evidence. During treatment, we attempted to answer the following questions which arose over time relative to patient outcome: a) which is the best dosage regimen? b) how long are brain $\mathrm{Cr}$ recovery times? c) how is neuropsychological impairment modified over time? d) is long term treatment safe for patients?

We updated previous data collected over time from the first Italian patients [1, 2, 6, 10-12] and we reviewed their long term outcomes in relation to clinical, neuropsychological, biochemical and toxicological findings after 10/15 years of Cr supplementation per os.

\section{Methods}

\section{Study sample}

Four patients from two related families are included in this report: two sisters (P1, P2, case index), diagnosed at 4 and 6 years respectively [1], and their brother (P4, neonatal diagnosis) [10] from family I and one male
(P3) from family II, diagnosed at 2 years [6]. Their pedigree is already reported in our previous publication [6].

These subjects presented hyposomia, mild hypotonia, clumsiness, developmental delay with mild or moderate intellectual disability and severe language impairment $[1,6]$.

This research is part of a more general project on the treatment of primary $\mathrm{Cr}$ defects approved by the Stella Maris Institute Ethics Committee. Informed written consent was obtained from parents of each patient, before starting treatment trial with $\mathrm{Cr}$ per os.

DNA sequence analysis of $A G A T$ was performed on each patient $[2,6,10]$ and in order to understand better the role of enzymes involved in Cr metabolism disorders, a study of GAMT (OMIM 601240) was also performed on the two families [6].

Biochemical analyses of $\mathrm{Cr}$ and GAA in plasma and urine were performed in order to monitor $\mathrm{Cr}$ status in body fluids and therapeutic compliance of patients through follow-up. Galenic Cr-monohydrate supplementation per os in P1-P3 was initially administered at $400 \mathrm{mg} / \mathrm{kg}$ subdivided in 3 doses daily. After 6 years, this was reduced to $200 \mathrm{mg} / \mathrm{kg}$ for P1, P2 and to $300 \mathrm{mg} / \mathrm{kg}$ for P3 [11]. After about 10 years, it was further reduced to $100 \mathrm{mg} / \mathrm{kg} /$ die in P1, P2, P3, subdivided in two administrations. This dosage has been maintained until the present. Treatment of $\mathrm{P} 4$ started with $\mathrm{Cr}$ at $100 \mathrm{mg} / \mathrm{Kg} /$ day at 4 months of life [10] and remained substantially unchanged until the age of 10 .

Since 2007, when the report on a 6-year outcome of our first 3 AGAT-d patients was published [11], all patients regularly underwent clinical (biochemical and neuropsychological) and MRS assessments, annually for P4 and every 18-24 months for the others.

\section{Clinical assessment}

Clinical assessment consisted of monitoring: i) auxological data (weight, height and OFC); ii) routine laboratory evaluations (glycemia, BUN, creatininemia, hepatic enzymes, and urine examination); iii) $\mathrm{Cr}$ levels in blood and urine and plasma amino acids; iv) cognitive abilities by comprehensive neuropsychological evaluation. 
In addition, considering the chronic high doses of $\mathrm{Cr}$ supplementation, creatinine and BUN were also initially evaluated every 6 months at home in order to monitor renal function.

Muscle strength was assessed after 11 and 15 years of follow-up by clinical grading scale (MRC scale).

$\mathrm{Cr}$ and GAA analysis in plasma and urine were performed by GC/MS [10] and plasma amino acids by an amino acid analyzer (JLC-500/V, Jeol, Japan).

Serial neuropsychological assessments were performed initially by means Griffiths Scales, Performance Scales of Wechsler Preschool and Primary Scale of Intelligence (WPPSI), visuomotor integration abilities test, language evaluation including productive and receptive vocabulary, sentence comprehension, and sentence repetition test [1, $6,10]$. Successively, all patients were monitored by Wechsler Intelligence Scale for children (WISC-r and WISC-III), Wechsler Adult Scale of Intelligence (WAIS-r) and WPPSI [12, 13]; in the last exam for P1-P3 by the Wechsler Adult Scale of Intelligence-IV Edition [12, 14] and for $\mathrm{P} 4$ by the Wechsler Intelligence Scale for Children-IV Edition [13]. These scales give an overall assessment of cognitive abilities for adults, young children and adolescents, respectively; providing a total score of Intelligence Quotient (TIQ) and four composite scores, which measure specific cognitive domains: Verbal Comprehension (VC), Visual-perceptual Reasoning (VPR), Working Memory (WM) and Processing Speed (PS). Adaptive functioning in motor, communication, daily living and socialization domains was assessed using the Vineland Adaptive Behaviour Scales (VABS) overtime [1, 6, 15].

\section{MRS assessment}

1H-MRS was performed with $1.5 \mathrm{~T}$ clinical scanner (LX Signa Horizon 1.5 GE Healthcare, Milwaukee, WI, USA) and data were acquired from voxel (VOI) of 3.4 cc placed in parietal cortical gray matter $[1,6,10]$. Since 2007, we have monitored all patients also by $31 \mathrm{P}-$ MRS, performed in the same session using the same MR system operating at $25.86 \mathrm{MHz}$. Data were collected with a surface flexible spectroscopy coil placed around the head at maximum diameter, applying a hard pulse. Spectral width was $2500 \mathrm{~Hz}$ and 1024 complex data points were sampled with a TR of $4 \mathrm{~s}$, a flip angle of 60 for a total of 128 averages $[11,16]$. Phosphocreatine $(\mathrm{PCr})$ and other high-energy phosphates such as inorganic phosphate $(\mathrm{Pi})$ and nucleoside triphosphates (gamma-ATP, alfa-ATP and beta-ATP) were measured in terms of a ratio with respect to phosphodiester signal (PDE) [11]. PDE signal was chosen as internal reference since it demonstrated a steady signal amplitude in both normal subjects and in patients in this study and because this metabolite is not included in any known metabolic circuit for cellular ATP production. Spectra were processed with SAGE software package [11, 17]; $\mathrm{pH}$ was calculated from shift in resonance position of inorganic phosphate $(\mathrm{Pi})$ peak compared to resonance position of $\mathrm{PCr}[11,17]$.

\section{Results}

\section{Clinical assessment}

All patients showed a homozygous mutation c. $446>\mathrm{A} /$ p.Trp149* (stop mutation) in $A G A T[2,6,10]$. P1, P2 and P3 with their parents and 10 additional subjects of the pedigree were analysed by sequencing also GAMT. A sequence variation in exon 6 (T209M) at nt position $4024 \mathrm{C}>\mathrm{T}$ of GAMT was disclosed, resulting in an amino acid change from threonine to methionine. The T209M sequence variation (dbSNP: rs 17851582) was carried heterozygously by 13 subjects and homozygously by 2 subjects (P1 and her asymptomatic father). However, normality of GAMT activity confirmed that this variation was non-pathogenic, without any clear consequences on enzyme protein function [6].

Plasma and urine $\mathrm{Cr}$ levels at diagnosis, after 5 years of $\mathrm{Cr} 200 \mathrm{mg} / \mathrm{Kg} /$ day (11-year follow-up) and 4 years of Cr $100 \mathrm{mg} / \mathrm{Kg} /$ day (15-year follow-up) for P1, P2, P3, and after 10-year follow-up for $\mathrm{P} 4$, respectively, are reported in Table 1. These data are different from those reported in the first papers on these patients $[1,6]$, probably due to the different techniques adopted for measuring low GAA and $\mathrm{Cr}$ concentrations. Cr levels increased under supplementation at all dosages compared to initial status, with highest concentrations at largest doses used. This was more evident in urine samples where very high levels of $\mathrm{Cr}, 4$ to 10 times above the maximum reference value, were observed. Plasma $\mathrm{Cr}$ concentrations were otherwise within the normal range for dosages under $200 \mathrm{mg} / \mathrm{kg} /$ day.

Cr supplementation was reduced to $100 \mathrm{mg} / \mathrm{kg} /$ day in two administrations for P1, P2 and P3 after 11 years of treatment and have remained at this level until today, when a total amount of $3 \mathrm{~g} /$ day was adopted based on presumed daily need in humans [18].

Patient 4, supplemented with unchanged protocol since the first month of life $(100 \mathrm{mg} / \mathrm{kg} /$ day $)$, showed stable $\mathrm{Cr}$ levels in blood with a remarkable reduction in urine at the last exam (after 10 years of treatment), in line with the dose reduction due to weight gain, corresponding to about $60-70 \mathrm{mg} / \mathrm{kg} /$ day (Table 1 ).

Fasting plasma amino acids analysis showed normal results for all amino acids involved in $\mathrm{Cr}$ metabolic cycle which could be affected by long term $\mathrm{Cr}$ supplementation.

During chronic Cr supplementation, auxological data rapidly increased in all symptomatic patients, raising in less than one year from p 3-50 and to p 75-85 after 2 years of treatment. On the contrary, the asymptomatic patient 
Table 1 Plasma, urine and brain concentrations of $\mathrm{Cr}$ and GAA in AGAT-d patients at diagnosis and after different treatment

\begin{tabular}{|c|c|c|c|c|c|c|c|c|c|c|c|c|c|c|}
\hline \multirow[t]{3}{*}{$\mathrm{Cr}$ dose (mg/kg/day) } & \multirow{2}{*}{\multicolumn{2}{|c|}{$G A A \mu M$}} & \multicolumn{4}{|l|}{ T0 } & \multicolumn{4}{|l|}{$\mathrm{T} 1$} & \multicolumn{4}{|l|}{$\mathrm{T} 2$} \\
\hline & & & \multicolumn{2}{|l|}{$\mathrm{Cr} \mu \mathrm{M}$} & \multirow{2}{*}{$\begin{array}{r}\text { CrmM } \\
\text { Brain }\end{array}$} & \multirow[t]{2}{*}{ PCr/PDE } & \multicolumn{2}{|l|}{$\operatorname{Cr} \mu M$} & \multirow{2}{*}{$\begin{array}{r}\mathrm{Cr} m \mathrm{MM} \\
\text { Brair }\end{array}$} & \multirow{2}{*}{ PCr/PDE } & \multicolumn{2}{|c|}{$\mathrm{Cr} \mu \mathrm{M}$} & \multirow{2}{*}{$\begin{array}{r}\mathrm{Cr} m \mathrm{M} \\
\text { Brai }\end{array}$} & \multirow{2}{*}{$\begin{array}{l}P C r / P D E \\
\text { in }\end{array}$} \\
\hline & $P$ & $U$ & $P$ & U & & & $\mathrm{P}$ & $U$ & & & $P$ & U & & \\
\hline P1 & n.d. & 2.45 & 5.23 & 146 & 1.10 & 0.73 & 28.33 & 9,784 & 3.77 & 1.11 & 51.9 & 6,445 & 3.9 & 1.40 \\
\hline P2 & n.d. & 2.16 & 5.41 & 133 & 1.05 & 0.76 & 38.67 & 37,489 & 3.86 & 1.15 & 26.2 & 9,459 & 3.2 & 1.35 \\
\hline P3 & 0.10 & 1.34 & 4.59 & 138 & 1.33 & 0.76 & 136.0 & 44,736 & 3.56 & 0.86 & 31.5 & 756 & 3.5 & 0.87 \\
\hline$P 4^{\mathrm{a}}$ & 0.13 & 0.54 & 16.22 & 25 & 0.15 & n.a. & 51.2 & 13,886 & 4.30 & 0.96 & 45.3 & 5,843 & 4.0 & 1.07 \\
\hline range: & $0.22-3.14$ & $56-698$ & 18-141 & $200-5500$ & $4.37+0.44$ & $1.40+0.14$ & & & & & & & & \\
\hline
\end{tabular}

$P$ plasma, $U$ urine, n.d. not detectable, n.a. not available

${ }^{\mathrm{a}} \mathrm{Cr}$ dose stable at $100 \mathrm{mg} / \mathrm{kg} /$ day overtime

Data were recorded at T0 (diagnosis), T1 (after 5 years of $\mathrm{Cr}$ 200, 300, $100 \mathrm{mg} / \mathrm{Kg} /$ day for P1-P2, P3 and P4, respectively) and at T2 (last observation at $100 \mathrm{mg} / \mathrm{Kg} / \mathrm{day}$ for all patients)

showed normal growth since the first months of life, with similar increases after 2 years of treatment (about 4 years at age).

Weight gain in all patients increased to p 90-95 after few years of chronic $\mathrm{Cr}$ administration and have remained at this level until now, despite a low calorie diet.

In all patients, high body mass indexes (BMI) were observed, especially in pre-pubertal age (Fig. 2), similarly for muscle bulk and muscle strength (grade 5 of MRC scale).
In the first years of therapy, patients presented polyuria and polydipsia. In addition, an occasional and transient diarrhea was observed when patients increased dosages to adjust for weight gain.

Routine laboratory evaluations were normal and patients did not show any other adverse effects.

Urinary sediment was also analyzed in all patients and none presented urine crystals, except for P3, who, at 10 years, had an episode of a kidney stone with no symptoms and spontaneously remittance after abundant

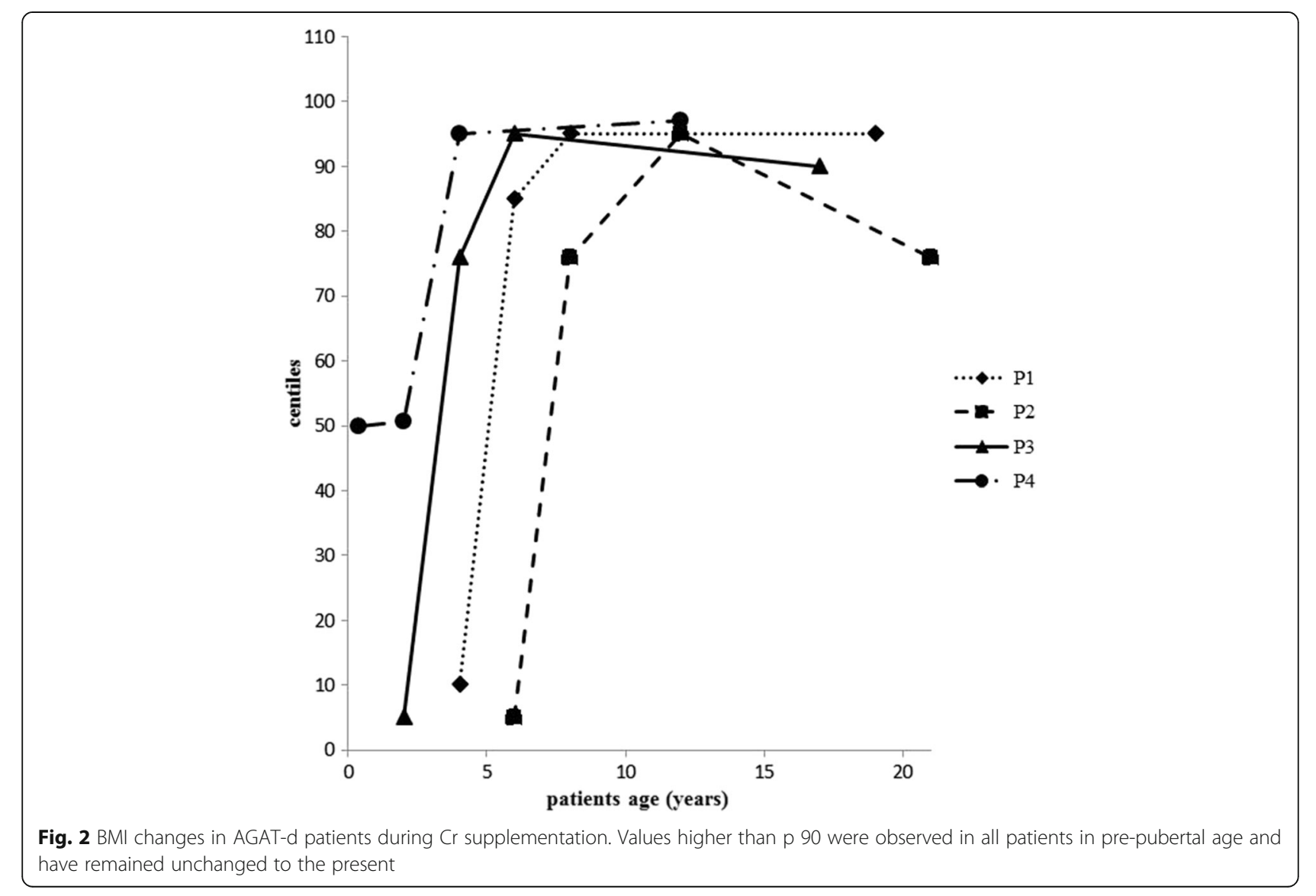


hydration therapy. Daily urinary clearance and proteinuria were normal. P3 was thereafter monitored by renal ultrasound and urine examination every 6 months for three consecutive years, with no abnormal findings.

All patients have continued to participate in psychomotor and speech rehabilitation programs at home since diagnosis (2-3 times a week). They presented residual expressive speech problems, but achieved educational milestones in secondary school with special-education teachers, except for P4 who is now attending the fourth grade of primary school without any special aid and with a good profile. Educational and social level of family I, as well as dialect influences, could partially account for this problem. In addition, the environment of family II (divorced, poorly-educated parents and relatives, periods of incarceration of father and other factors), may have influenced compliance in supplementation and rehabilitation treatment and consequently cognitive development of P3.

P1-P3 presented similar profiles on intelligence scales consisting of a greater fall in subtests designed to assess VC (VC Index, VCI) and nonverbal (VPR Index, VPRI) cognitive skills, and relatively better scores in subtests aimed at assessing WM (WM Index, WMI) and PS (PS Index, PSI). In fact, in all three patients, PSI statistically [14] differed from VCI and PRI and in P1 and P3 it also diverged from WMI. Cognitive difficulties of P1-P3 mainly affected processes of reasoning and knowledge building, both in verbal and nonverbal domains, while they showed better skills in working memory, attention, speed of execution and visual-motor integration (Fig. 3). A different profile was observed in P4, indicating only a slight fall in WMI, which was statistically lower than the others indices [13]. In comparison with normal TIQ of
P4 (98), P1-P3 presented deficient scores (41, 50 and 61, respectively), with extensive falls in investigated areas, expression of intellectual disability which remained stable over years and was more severe in the older girl who started treatment after 6 years of age (Fig. 3).

However, P1 and P2, now 23 and 20 years respectively, obtained a high-school diploma: the oldest obtained a Hospitality Training Institute diploma and now works as a waitress in a pizzeria, while her younger sister earned a Biology Science Institute diploma and she is now studying with support for admission to a university bachelor program in biology. P3, now 18 years, is attending the last year of high-school (Hospitality Training Institute) with a lower profile than the other girls.

\section{MRS assessment}

Consecutive MRS examinations have demonstrated that $\mathrm{Cr}$ depletion in AGAT-d patients is reversible under $\mathrm{Cr}$ supplementation. To our knowledge, only our patients were monitored by Proton (1H-) and Phosphorus (31P-) MRS in the same session during their long-term follow-up. Table 1 and Fig. 4 summarize the 1H-MRS and 31P-MRS data during follow-up.

Initial dosage of $\mathrm{Cr}$ supplementation was $400 \mathrm{mg} / \mathrm{kg} / \mathrm{day}$, corresponding to about 20 times daily $\mathrm{Cr}$ requirement for P1- P3, while P4 started his supplementation with a dose of $100 \mathrm{mg} / \mathrm{kg} /$ day. At $1 \mathrm{H}$-MRS, an increase of $\mathrm{Cr} / \mathrm{PCr}$ cerebral content was observed rapidly after supplementation, reaching over $90 \%$ in the three symptomatic subjects [1, 6], while in $\mathrm{P} 4, \mathrm{Cr}$ replenishment peaked at 60-65\% [10]. Reducing Cr daily dose to $200 \mathrm{mg} / \mathrm{kg}$ in $\mathrm{P} 1-\mathrm{P} 3$ did not lead to any differences in $\mathrm{tCr}$ and $\mathrm{PCr}$ except for an unexpected drop in $\mathrm{PCr} / \mathrm{PDE}$ ratio from 1.32 to 0.83 in $\mathrm{P} 3$ after an abrupt $\mathrm{Cr}$ reduction to

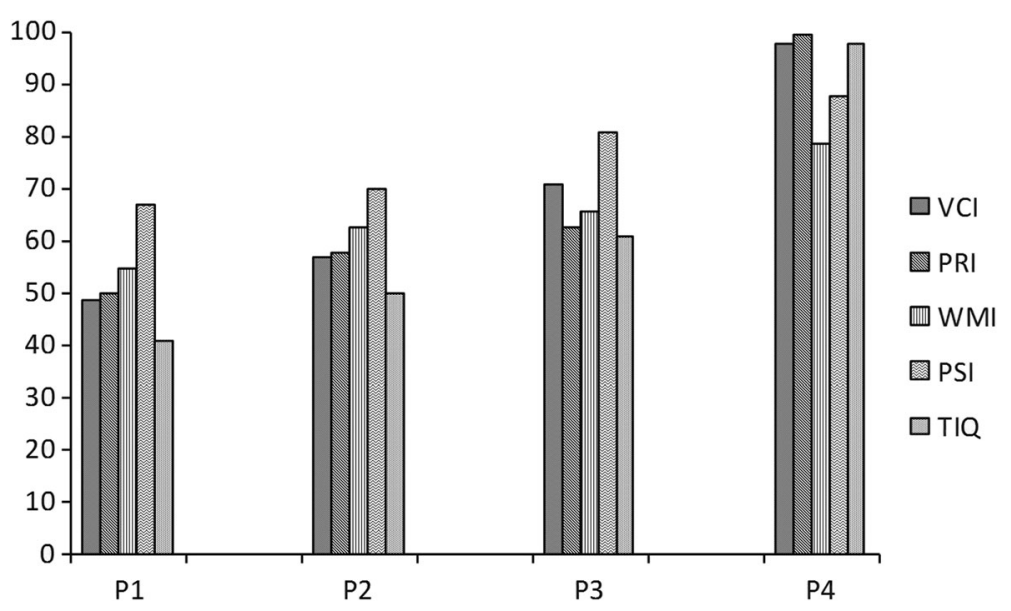

Fig. 3 Psychometric evaluations by WAIS-IV or WISC-IV intelligence scales in AGAT-d patients after 15 years of clinical follow-up. Columns represent the scores obtained from each patient in different domains which contribute to the Total Intelligence Quotient (TIQ). Verbal Comprehension Index (VCI) and Visual-Perceptual Reasoning Index (PRI) in the asymptomatic patient were normal differently from his symptomatic relatives. Working Memory Index (WMI) and Processing Speed Index (PSI) in symptomatic patients presented better skills than the others 


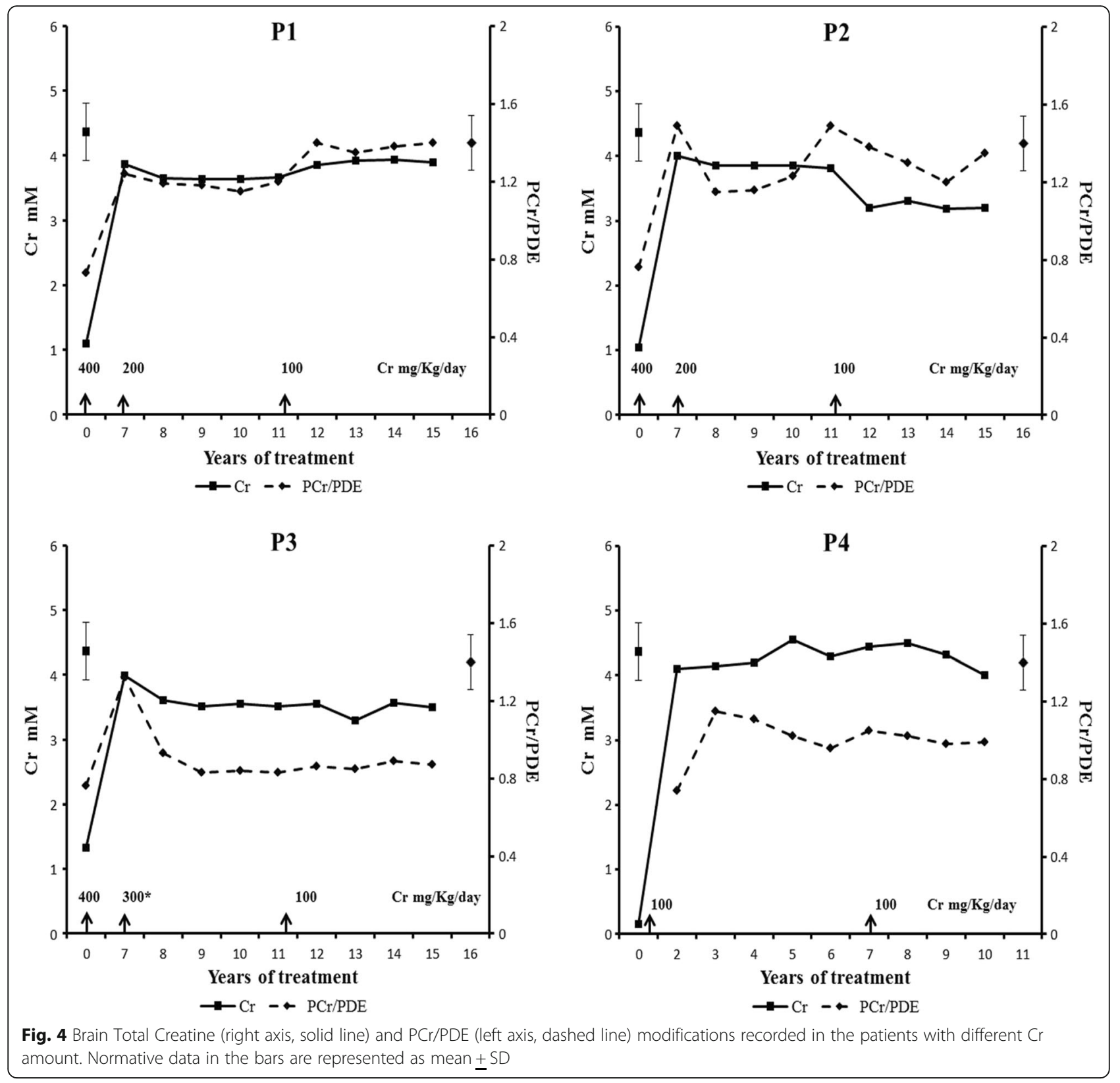

$200 \mathrm{mg} / \mathrm{kg} /$ day. In order to avoid a further decrease of brain $\mathrm{Cr}$, daily supplementation was immediately increased to $300 \mathrm{mg} / \mathrm{kg} /$ day [11].

During the following years, $\mathrm{Cr}$ daily supplementation was reduced to $100 \mathrm{mg} / \mathrm{Kg}$ in P1-P3 with no substantially differences in comparison to the highest doses (Table 1). A slight decrease in brain $\mathrm{tCr}$ peak was observed in P2 and P3 with a concomitant reduction in $\mathrm{PCr}$ peak compared to the results after 1 year at $200 \mathrm{mg} / \mathrm{Kg} /$ day $[11,12]$.

Brain $\mathrm{Cr}$ and $\mathrm{PCr} / \mathrm{PDE}$ values in $\mathrm{P} 4$ showed an unchanged trend overtime, maintaining normal levels within $1 \mathrm{SD}$. Pi, ATP and $\mathrm{pH}$ in the brain were stable and within normal values in patients during all the above-mentioned treatments.

\section{Discussion}

It has been well recognized that $\mathrm{Cr}$ supplementation is able to restore brain pool in patients with AGAT-d but unfortunately little information is available in terms of dosage, clinical progression and disease outcome. This study aimed at providing an update of results achieved in 4 AGAT-d patients after 15 (P1-P3) and 10 years (P4) of $\mathrm{Cr}$ supplementation, respectively.

Our experience tells us that the first critical step in diagnosis of AGAT-d consists of a proper quantitative 
measure of $\mathrm{Cr}$ and GAA in body fluids. As reported in the first paper by our group [1], misleading results could arise from urine samples, where levels of two key metabolites were near the lower end of normal value range, probably reflecting excretion of $\mathrm{Cr}$ assumed in food. Improvements in diagnostic techniques have eliminated this problem, and successive measurements in the same patients demonstrated that $\mathrm{Cr}$ and GAA levels in AGAT-d were below control range both in blood and urine indicating that they are, together with cerebral $\mathrm{Cr}$ levels, the best markers for AGAT-d.

The decision to set the initial dose at $400 \mathrm{mg} / \mathrm{Kg} /$ day in five administrations was based on an adopted schedule in a patient with GAMT deficiency, the first described inborn error of $\mathrm{Cr}$ metabolism [19], where $50 \%$ replenishment of brain $\mathrm{Cr}$ pool after 12 weeks of supplementation was reported. Similar brain $\mathrm{Cr}$ restoration was observed in our patients after 9 months of therapy, which resulted in $80 \%$ of normal [1] in gray matter and cerebellum, with concomitant improvements in cognitive development and other clinical symptoms.

Similar ameliorations have been observed in all the other patients $[8,9,20]$; for one of them the dosage was increased up to $800 \mathrm{mg} / \mathrm{Kg} /$ day and then reduced to $500 \mathrm{mg} / \mathrm{kg} /$ day without different replenishment of brain $\mathrm{Cr}$, while progress in cognitive development was noticed after start of treatment [8].

Even though all patients showed clinical improvements under $\mathrm{Cr}$ supplementation; in patients where treatment started at a later age, an amelioration in muscle strength/ endurance $[9,20]$ and in adaptive functioning [9] was limited, while cognitive and speech remained unchanged. Taken together, these two findings support the hypothesis that myopathy may be a clinical sign of disease only at an older age $[7,20]$ and that irreversible brain damage occurs when treatment is delayed. Our data seem to confirm this hypothesis because all patients diagnosed at a young age did not show muscle deficiency and cognitive recovery was lower for patients older at diagnosis. In fact, TIQ of P1 did not change despite brain Cr recovery. Conversely, early treatment prevents adverse developmental outcomes, as demonstrated in P4 $[10,12]$ and in the other young patient who started treatment at 16.5 months [8]; both of them, currently 11 and 12 years of life respectively, have achieved normal development with excellent educational milestones. According to previous assessments [12], WISC-IV score in the asymptomatic patient was within normal range, indicating that his intellectual development proceeded typically overtime with a slight residual speech impairment, also present to a greater degree in his sisters.

The placental $\mathrm{Cr}$ delivery to the foetus during pregnancy is important for an adequate growth and a development in normal conditions [21, 22], and crucial in Cr disorders, as demonstrated by the normal clinical presentation at birth of P4. Maternal supplementation during pregnancy could have provided higher levels of $\mathrm{Cr}$ in the affected newborn, but she refused any prior treatment as well as any prenatal diagnosis. In order to correct $\mathrm{Cr}$ depletion, since the infant was breastfed, we initially tried to supplement the mother's diet with Cr. Although this approach resulted in an increase of $\mathrm{Cr}$ concentration in maternal milk, $\mathrm{Cr}$ increase in the infant's blood, urine and brain was unremarkable [10].

Considering the clinical results in our 4 patients and taking into account the limitations of this study, some recommendations based on the evidence might be useful in the management of AGAT-d patients. Daily dose was reduced initially to $200 \mathrm{mg} / \mathrm{kg} /$ day in $\mathrm{P} 1$ and P2 after 6 years, and in P3 after 5 years, respectively, with good results [11]. Subsequently, based on MRS data obtained in the youngest patient, daily supplementation of the 3 older patients was gradually reduced to $100 \mathrm{mg} / \mathrm{Kg} /$ day with a parallel decrease of $\mathrm{Cr}$ levels in blood and urine, but not in the brain where $\mathrm{Cr}$ and $\mathrm{PCr} / \mathrm{PDE}$ remained stable or decreased only slightly (Fig. 4). The slight reduction in brain $\mathrm{Cr}$ levels observed at the dose of $100 \mathrm{mg} / \mathrm{Kg} /$ day in these patients seems to have no effect on their cognitive performances, which are stable in the same range (Fig. 3), Indeed, in the asymptomatic newborn, in which the initial dosage was lower $(100 \mathrm{mg} / \mathrm{Kg})$, a $65 \%$ $\mathrm{Cr}$ restoration in brain required a longer period (about 18 months) than in his affected relatives, in which about 90\% of Cr replenishment was observed after 12 months of therapy $[1,10]$. Considering that the blood brain barrier is more permeable in developing brain and $\mathrm{Cr}$ was well absorbed in all patients, as demonstrated by $\mathrm{Cr}$ concentrations in plasma, the differences in brain recovery time observed in the 4 patients could be ascribed to the different dosage regimens adopted. Low doses require more time to restore $\mathrm{Cr}$ in brain to the highest possible levels without affecting clinical improvement, thus avoiding peripheral compartment overloading and possible toxic effects. These findings seem to be confirmed by data of the other young AGAT-d patient [8], in which doses higher than $400 \mathrm{mg} / \mathrm{Kg}$ did not improve $\mathrm{Cr} / \mathrm{NAA}$ ratio more than $70 \%$ of controls and increased the risk of renal damage. In our patients, reduction of doses to less than $100 \mathrm{mg} / \mathrm{kg} /$ day normalized $\mathrm{Cr}$ in blood and urine, with the best profile in $\mathrm{P} 4$, who is biochemically similar to his normal peers.

1H MRS acquisition of $\mathrm{P} 4$ at the age of 8 years showed a slight reduction of cerebral $\mathrm{Cr}$ as in $\mathrm{P} 3$ at the same age, but not in the female patients, despite their different dosage regimens.

In our patients, $100 \%$ recovery of cerebral Cr seems unfeasible, whatever treatment schedule was used; the highest $\mathrm{Cr}$ replenishment was found in $\mathrm{P} 4$ at about 4 years (98\%). Although timing dosages for all reported AGAT-d patients are incomplete, we suppose that the 
principal factor accounting for this effect is the down regulation of the transporter protein at high $\mathrm{Cr}$ concentrations [5, 23]. However, in the mouse model of AGAT-d, total $\mathrm{Cr}$ brain accumulation continues over time up to the normal concentrations of wild-type mice [24], while in AGAT-d patients brain $\mathrm{Cr}$ always remains below control values. Partial recovery of cerebral $\mathrm{Cr}$ in patients could represent a missing amount deriving from cerebral AGAT-d synthesis. Endogenous $\mathrm{Cr}$ synthesis contributes to brain needs for a negligible part (no more than $20 \%$ ) as demonstrated by mouse models of $\mathrm{Cr}$ transporter (CrT) deficit $[24,25]$, where it is reduced in both the cortex and hippocampus to about $18-20 \%$ of control groups. In addition, brain $\mathrm{Cr}$ in $\mathrm{CrT}$ deficient patients is absent or strongly reduced when assessed by $1 \mathrm{H}-\mathrm{MRS}$; thus supporting the hypothesis that endogenous synthesis does not compensate for loss of $\mathrm{Cr}$ deriving from periphery. These considerations might account for the partial brain $\mathrm{Cr}$ replenishment in AGAT-d patients which does not reach the same level of controls and remains stable below 90\% even when $\mathrm{Cr}$ transport is forced with high doses. However, despite the partial restoration of brain $\mathrm{Cr}$ pool, the clinical status of these patients improve significantly during treatment and, in the one who was early treated, typical somatic and psychomotor development was observed.

Considering the best dosage regimen, we can hypothesize that oral $\mathrm{Cr}$ supplementation efficiently restores cerebral levels even at lower doses, although more slowly, after a short period at high doses $(400 \mathrm{mg} / \mathrm{kg} / \mathrm{day})$ in older patients or at $100 \mathrm{mg} / \mathrm{kg} / \mathrm{day}$ in younger ones. The small number of patients included in this study and their common genetic background, affecting both the clinical course and treatment response, do not permit us to suggest clinical guidelines suitable for all patients with AGAT-d. However, as in other rare inborn errors of metabolism, each patient constitutes his/her own control and for this reason the optimal dosage treatment response is not an unquestionable statement. Furthermore, clear evidence for the effect of $\mathrm{Cr}$ on clinical improvement in AGAT-d patients arises from the observation that patient status normalizes during treatment.

\section{Conclusions}

Despite the small number of patients, we conclude that $100 \%$ recovery of cerebral $\mathrm{Cr}$ seems unfeasible, whatever treatment schedule used, but there was no correlation between $\mathrm{Cr}$ levels and cognitive improvement. Cr treatment was well tolerated even at high doses, although side effects of weight gain and kidney stones were observed.

As indicated by the normal clinical development of $\mathrm{P} 4$, an early diagnosis is recommended for a timely treatment, suggesting the importance of NBS. Given the lack of a reliable biomarker in bloodspot for this inborn error of metabolism, it might be useful to consider other new options of treatment, such as untargeted metabolomics and/or genomic NBS. In the meantime, we should take in account AGAT-d in all patients presenting development delay, hypotonia, myopathy and language impairment in order to allow for an early diagnosis thus enabling treatment.

\begin{abstract}
Abbreviations
1H-MRS: Proton magnetic resonance spectroscopy; 31P-MRS: Phosphorus magnetic resonance spectroscopy; AGAT: Arginine:glycine amidinotransferase; AGAT-d: Arginine:glycine amidinotransferase deficiency; BMI: Body mass index; BUN: Blood urea nitrogen; Cr: Creatine; CrT: Creatine transporter;

GAA: Guanidinoacetic acid; GAMT: Guanidinoacetate-methyltransferase; GAMT-d: Guanidinoacetate-methyltransferase deficiency; GC/

MS: GasChromatography/Mass-spectrometry; MRS: Magnetic resonance spectroscopy; NBS: Newborn screening; OFC: Occipito frontal circumference; PCr: PhosphoCreatine; PDE: Phosphodiester; Pi: Phosphorus inorganic; PS: Processing speed; TIQ: Total Intelligence quotient; VABS: Vineland adaptive behaviour scales; VC: Verbal comprehension; VOI: Voxel of Interest; VPR: Visualperceptual reasoning; WAIS-r: Wechsler adult scale of intelligence; WISC-r and WISC-III: Wechsler intelligence scale for children; WM: Working memory; WPPSI: Wechsler preschool and primary scale of intelligence
\end{abstract}

\section{Acknowledgments}

A special thanks to V. Corsentino for the English review. The authors address special thanks to all patients and their families for their precious cooperation.

\section{Funding}

This work was partially supported by a grant from the Italian Ministry of Health (RC 2011, 2013, 2014).

\section{Availability of data and materials}

The datasets used and7or analysed during the current study available from the corresponding author on reasonable request.

\section{Authors' contribution}

RB, MGA, GC: Study concept and design. RB, MGA, MC, CC, MT: Acquisition of data. RB, MGA, MC, MT, GC: Analysis and interpretation of data. RB, MGA, CC: Drafting of the manuscript. RB, GC: Critical revision of the manuscript for important intellectual content. RB, GC: Study supervision. All authors read and approved the final manuscript.

\section{Authors' information}

$\mathrm{RB}$ is a MD and PhD, senior researcher in Research and Care Institute (IRCCS), Fondazione Stella Maris, specialist in Neurological and Psychiatric disorders in developmental age. She is specialized on rare diseases in childhood. MGA is a biologist, responsible of all biochemical dosage performed in the Neurochemistry Lab in IRCCS Stella Maris. MC is a MD, PhD in Child Neurology and Psychiatry, researcher collaborator of RB at IRCCS Stella Maris. CC is a psychologist, expert in neuropsychological profiles during developmental age. MT is a medical physicist, responsible of the Magnetic Resonance Lab at IRCCS Stella Maris, with particular expertise in magnetic resonance spectroscopy (MRS). She elaborated the MRS data. GC is the scientific director of IRCCS Stella Maris, director and supervisor of all research projects of the institute.

\section{Competing interests}

The authors declare that they have no competing interests.

\section{Consent for publication}

The parents of the patients enrolled in the study filled out a consent form in order to consent the publication of any individual person's data (including individual details and/or images).

\section{Ethics approval and consent to participate}

The research was part of a more general project on the treatment of primary $\mathrm{Cr}$ defects approved by the Stella Maris Institute Ethics Committee (RC2011, 
2012). Informed written consent was obtained from the parents from the first participation of the study.

\section{Author details}

'Department of Developmental Neuroscience, IRCCS Fondazione Stella Maris, Viale del Tirreno 331, Calambrone, 56128 Pisa, Italy. ${ }^{2}$ Department of Developmental Neuroscience, MRI Laboratory, IRCCS Fondazione Stella Maris, Calambrone, Pisa, Italy. ${ }^{3}$ Department of Clinical and Experimental Medicine, University of Pisa, Pisa, Italy.

Received: 1 June 2016 Accepted: 20 January 2017

\section{Published online: 02 February 2017}

\section{References}

1. Bianchi MC, Tosetti M, Fornai F, Alessandrì MG, Cipriani P, De Vito G, Canapicchi R. Reversible brain creatine deficiency in two sisters with normal blood creatine level. Ann Neurol. 2000;47:511-3.

2. Item CB, Stöckler-Ipsiroglu S, Stromberger C, Mühl A, Alessandrì MG, Bianchi MC, Tosetti M, Fornai F, Cioni G. Arginine:glycine amidinotransferase deficiency: the third inborn error of creatine metabolism in humans. Am J Hum Genet. 2001;69:1127-33.

3. Stockler S, Battini R, De Grow T, Schulze A. Disorder of Creatine Metabolism In: Blau N, Hoffmann G, Leonard J, Clarke TR, editors. Physician's Guide to the treatment and Follow-Up of Metabolic Diseases. Berlin: Springer Verlag-Berlin; 2006. p. 255-65.

4. Stromberger C, Bodamer O, Stockler-Ipsiroglu S. Clinical characteristics and diagnostic clues in inborn errors of creatine metabolism. J Inher Metab Dis. 2003;26:299-308

5. Wyss M, Kaddurah-Daouk R. Creatine and creatinine metabolism. Physiol Rev. 2000:80:1107-213.

6. Battini R, Leuzzi V, Carducci C, Tosetti M, Bianchi MC, Item CB, Stockler-Ipsiroglu S, Cioni G. Creatine depletion in a new case with AGAT deficiency: clinical and genetic study in a large pedigree. Mol Genet Metab. 2002;77:326-31.

7. Stockler-Ipsiroglu S, Apatean D, Battini R, DeBrosse S, Dessoffy K, Edvardson S, Eichler F, Johnston K, Koeller DM, Nouioua S, Tazir M, Verma A, Dowling MD, Wierenga KJ, Wierenga AM, Zhang V, Wong LJ. Arginine:glycine amidinotransferase (AGAT) deficiency: clinical features and long term outcomes, in 16 patients diagnosed worldwide. Mol Genet Metab. 2015;116(4):252-9.

8. Ndika JD, Johnston K, Barkovic JA, Wirt MD, O'Neill P, Betsalel OT, Cornelis J, Salomons GS. Developmental progress and creatine restoration upon long-term creatine supplementation of a patient with arginine:glycine amidinotransferase deficiency. Mol Genet Metab. 2012;106:48-54.

9. Edvardson S, Korman SH, Livne A, Shaag A, Saada A, Nalbandian R, AlloucheArnon H, Gomori JM, Katz-Brull R. L-arginine:glycine amidinotransferase (AGAT) deficiency: clinical presentation and response to treatment in two patients with a novel mutation. Mol Genet Metab. 2010;101:228-32.

10. Battini $R$, Alessandrì MG, Leuzzi $V$, Moro F, Tosetti M, Bianchi MC, Cioni G. Arginine:glycine amidinotransferase (AGAT) deficiency in a newborn: early treatment can prevent phenotypic expression of the disease. J Pediatr. 2006;148:828-30.

11. Bianchi MC, Tosetti M, Battini R, Leuzzi V, Alessandri' MG, Carducci $C$ Antonozzi I, Cioni G. Treatment monitoring of brain creatine deficiency syndromes: a $1 \mathrm{H}$ - and 31P-MR spectroscopy study. Am J Neuroradiol. 2007;28:548-54

12. Battini R, Casalini C, Casarano M, Alessandrì MG, Leuzzi V, Cioni G. Clinical and neuropsychological follow up of AGAT-d patients after ten years from the diagnosis. J Inherit Metab Dis. 2011;34 Suppl 3:S49-S286. P-143, page S126.

13. Wechsler D. WISC-IV: Wechsler intelligence scale for children. San Antonio, TX: the psychological corporation 2003. Adattamento italiano a cura di a. Orsini e L. Pezzuti. Firenze: Giunti O.S; 2012.

14. Wechsler D. WAIS-IV: wechsler adult intelligence scale. San antonio, TX: the psychological corporation, 2008. Adattamento italiano a cura di a. Orsini e L. Pezzuti. Firenze: Giunti O.S; 2013.

15. Chilosi A, Leuzzi V, Battini R, Tosetti M, Ferretti G, Comparini A, Casarano M, Moretti E, Alessandrì MG, Bianchi MC, Cioni G. Treatment with L-arginine improves neuropsychological disorders in a child with creatine transporter defect. Neurocase. 2008;14:151-61.

16. Provencer SW. Estimation of metabolite concentrations from localized in vivo proton NMR spectra. Magn Reson Med. 1993;30:672-67.
17. Schirmer T, Auer DP. On the reliability of quantitative clinical magnetic resonance spectroscopy of the human brain. NMR Biomed. 2000;13:28-36.

18. Wyss M, Wallimann T. Creatine metabolism and the consequences of creatine depletion in muscle. Mol Cell Biochem. 1994;133-134:51-66.

19. Stockler S, Holzbach U, Hanefeld F, Marquardt I, Helms G, Requart M, Hänicke W, Frahm J. Creatine in the brain: a new treatable in born error of metabolism. Paediatr Res. 1994;36:409-13.

20. Verma A. Arginine:glycine amidinotransferase deficiency: a treatable metabolic encephalomyopathy. Neurology. 2010;75:186-8.

21. Ellery SJ, LaRosa DA, Kett MM, Della Gatta PA, Snow RJ, Walker DW, Dickinson $\mathrm{H}$. Maternal creatine homeostasis is altered durimng gestation in the spiny mouse: is this a metabolic adaptation to pregnancy? BMC Pregnancy Childbirth. 2015;15:92-100.

22. Ellery SJ, Walker DW, Dickinson H. Creatine for women: a review of the relationship between creatine and the reproductive cycle and femalespecific benefits of creatine therapy. Amino Acids. 2016;48:1807-17.

23. Nabuurs $\mathrm{Cl}$, Choe CU, Veltien A, Kan HE, Van Loon LJ, Rodenburg RJ, Matschke J, Wieringa B, Kemp GJ, Isbrandt D, Heerschap A. Disturbed energy metabolism and muscular dystrophy caused by pure creatine deficiency are reversible by creatine intake. J Physiol. 2013;591:571-92.

24. Kurosawa Y, DeGrauw TJ, Lindquist DM, Blanco VM, Pyne-Geithman GJ, Daikoku T, Chambers JB, Benoit SC, Clark JF. Cyclocreatine treatment improves cognition in mice with creatine transporter deficiency. J Clin Invest. 2012;122:2837-46.

25. Baroncelli L, Alessandrì MG, Tola J, Putignano E, Migliore M, Amendola E, Gross C, Leuzzi V. Cioni G, Pizzorusso T. A novel mouse model of creatine transporter deficiency. F1000 Research. 2014;3:228. doi:10.12688/ f1000research. 5369 .

\section{Submit your next manuscript to BioMed Central and we will help you at every step:}

- We accept pre-submission inquiries

- Our selector tool helps you to find the most relevant journal

- We provide round the clock customer support

- Convenient online submission

- Thorough peer review

- Inclusion in PubMed and all major indexing services

- Maximum visibility for your research

Submit your manuscript at www.biomedcentral.com/submit
Biomed Central 